\title{
COMPUTATION AND MONITORING OF THE SOIL MOISTURE INDEX ON BULGARIAN TERRITORY
}

\author{
Olga Nitcheva $^{1 *}$, Borislav Milev ${ }^{2}$ \\ ${ }^{1}$ Institute of Mechanics, Bulgarian Academy of Sciences, 4 Acad. Bonchev \\ Str., Sofia, Bulgaria \\ ${ }^{2}$ European Politechnical University, 23 St.St. Kiril and Methody Str., Pernik, \\ Bulgaria
}

[Received 13 December 2016. Accepted 20 March 2017]

\begin{abstract}
The estimation and monitoring of the soil moisture index (SMI) on the Bulgarian territory is an important task from agricultural, fire and flood safety and water resources management aspects. It is not achievable by direct measurements as in the country there are only 20 field observation points. For the purpose adequate spatially distributed mathematical models must be employed. The paper demonstrates the implementation of the task by application of the Community Land Model (CLM) and all other procedures related to the preparation of GIS maps (Geographic Information Systems) for monitoring of monthly mean soil moisture index.
\end{abstract}

KEY WORDS: Soil moisture index, soil moisture estimation, precipitationrunoff models.

\section{General NOTES}

Drought is the shortage of water in the 1 meter thick upper soil layer. The wetness of that soil zone is of essential importance for the plants growth. The soil moisture of that layer is important for formation of the runoff, too, when by modelling considered is the threat for floods from expected high precipitations. Especially indicative and strongly dependent on weather conditions is the moisture of the $30 \mathrm{~cm}$ soil layer. The estimation and monitoring of the Soil Moisture Index for the territory of Bulgaria up to that depth is of importance for the country water resources management, the

agriculture, forest fires prediction, environmental status, and so on. The soil moisture value strongly depends on the land surface and soil profile water retaining and transport properties, well varying over the country territory. It depends also on the climatic effects territorially varying as well, though not so much. The direct field measurement on the spot is the most trustworthy way for its determination, but it is unachievable as the measuring points for Bulgaria must be several thousands. Therefore the estimation of the representative number of area mean soil moisture values

\footnotetext{
${ }^{*}$ Corresponding author e-mail: olgani@imbm.bas.bg
} 
for the whole country can evidently be performed only by numerical models. Field point measurements, carried out in limited number of stations, can to certain extent be used for assessment of the computed values realism.

The paper describes the methodology, the main advantages of the used model and the operational technology for calculations of representative soil moisture values, as well as for creation of digital country maps of the average monthly estimates of the Soil Moisture Index exemplified for 2013.

\section{MATHEMATICAL MODEL AND METHODOLOGY OF THE SOIL MOISTURE STUDY}

Basic application problem of spatially distributed hydrologic model, suitable for the regarded task, is input data providing the soil water transport properties and the time dependant atmospheric effects on the respective computational grid cells, throughout the country territory and the model degree of approximation to the mechanics of water and heat transport, through the soil profile and energy exchange between the soil surface and the atmosphere. The selection of a suitable for the purpose model should comply with these requirements.

In this study, the soil moisture is calculated by the rainfall - runoff model Community Land Model (CLM) of NASA, which is the land component of the NCAR (the US National Center for Atmospheric Research) Community Climate System Model (CCSM) [9]. Community Land Model (CLM) is a complex model, the third (highest) generation among the climate models. It works on Linux platforms with huge amount of data. The input information is in special format - Network Common Data Form (NetCDF). The model was acquired and put into usage during the research work of the author in the Institute of Environment and Sustainability (IES JRC EDO) [2], [5] in Italy and the Institute of Mechanics at the Bulgarian Academy of Sciences (BAS) in Bulgaria.

CLM model calculates the water balance between the precipitation, runoff, evapotranspiration and infiltration through the soil layer. The terrain surface grid in the study is assumed with resolution (cells) $5 \times 5 \mathrm{~km}$, containing the water transport and transformation properties data according to the topography, land cover, soil profile and vegetation (this resolution can be reduced to $1 \times 1 \mathrm{~km}$ in case of available data). The atmospheric forcing data are distributed in the computational grid nodes with cells $200 \times 200 \mathrm{~km}$. The availability of atmospheric forcing data as air temperature, air pressure, specific humidity, solar radiation, wind speed, precipitation with several hours time step and its compatibility with the model grid is an essential precondition for its application.

The main advantages of using the assumed model for the purpose, compared to other hydrological models, are as follows: 
- It provides realistic model of the infiltration process through the unsaturated zone by accurate dependencies, which take into account not only the gravity but as well, the porous and capillary uplift forces according to the degree of the wetness and its distribution giving the values of the soil moisture down the soil profile.

- The needed by the model meteorological input is supplied in this study with NASA atmosphere NCEP/NCAR Reanalysis data (globally gridded data from the US National Centers for Environmental Prediction (NCEP) and the US National Center for Atmospheric Research (NCAR)), gathered by weather observations from ships, planes, RAOBS (radiosonde observation), stations, satellite observations and other ways [3]. They are freely available and easy to use.

- The model is ready loaded with all the necessary input data, relating the country territory soils characteristics and land cover with resolution $5 \times 5 \mathrm{~km}$, taken from the International Geosphere - Biosphere Programme (IGBP) data base.

The first step to implementation of the task for the Soil Moisture Index (SMI) estimation consists in computation of the soil moisture monthly average value in the grid cells. The model executes the task through simulating the moisture transport process through the soil profile, during the assumed period (1 year in the case), with 6 hours long time increment. The next step follows the Soil Moisture Index (SMI) calculation. Its value explicitly indicates the real significance of the actual soil moisture value for the plants, which roots don't penetrate deeper than $30 \mathrm{~cm}$.

The indicator of drought Soil Moisture Index (SMI) is calculated by the following formula [10]:

$$
\mathrm{SMI}=\frac{5 \cdot(\mathrm{SM}-\mathrm{WP})}{(\mathrm{FC}-\mathrm{WP})}-5
$$

where SM is the modelled soil moisture value at $30 \mathrm{~cm}$ depth in $\mathrm{cm}^{3} / \mathrm{cm}^{3}$. WP is the plant wilting moisture value in $\mathrm{cm}^{3} / \mathrm{cm}^{3}$ - it is the point, where the soil moisture is not available for the plant roots and they die. It depends on the soil type ranging in the limits $0.05-0.25\left(\mathrm{~cm}^{3} / \mathrm{cm}^{3}\right)$. FC is the soil capacity $\left(\mathrm{cm}^{3} / \mathrm{cm}^{3}\right)-$ it is the maximum water that soil can retain. It depends on soil porosity and its range is in the limits $0.1-0.4\left(\mathrm{~cm}^{3} / \mathrm{cm}^{3}\right)$.

Table 1 shows the SMI and the corresponding degrees of drought. The table shows that the smaller is SMI the greater is the drought. It is seen by the given formula that SMI is 0 , when there is soil saturation and it can be bellow -5 in case of drought hazard. 
Table 1.

\begin{tabular}{|l|c||l|c|}
\hline \hline Drought conditions & SMI & Drought conditions & SMI \\
\hline Normal & -1 or high $(0)$ & Highly drought & $-4<-3$ \\
\hline Moderate drought & $-2<-1$ & Extreme drought & -5 or less \\
\hline Increased drought & $-3<-2$ & & \\
\hline
\end{tabular}

\section{CONSIDERATION OF THE MODELLED RESULTS REALISM COMPARING WITH OBSERVED VALUES}

Different model performance results were assessed in the carried out earlier detailed research They included computation of runoff, infiltration and soil moisture. Produced by the model runoff was compared by the field observation, made for the watershed of Topolnitza river, a tributary of Maritza river in Bulgaria [8]. The modelled values for the groundwater recharge were compared with field observed ones of the groundwater body Belene [4]. These comparisons showed good performance of the CLM for Bulgarian soil and climate conditions.

The calculated by the model soil moisture was compared to the field measured soil moisture values for April 2011 as well as, for March and April 2013 [6,7]. It has to be noted that model results are average for grid cell with resolution $5 \times 5 \mathrm{~km}$, or $25 \mathrm{~km}^{2}$, while the soil moisture measurements are point values. Thus, they cannot be expected to match with precision, but the direct field measurements can serve as an approximate criterion for the realism of the model.

The comparison of the results in many points shows proximity between the calculated and the measured soil moisture. The differences are in both directions, but in most cases they are bellow $15 \%$ within the soil layer 0-30 cm. However, at depth the difference of the results in most cases is significant. Measurements show decrease of soil moisture in depth, reaching the wilting point $0.15-0.20 \mathrm{~cm}^{3} / \mathrm{cm}^{3}$. It is due to the not much realistic moisture content, assumed in the model as initial condition. After long time simulation in the process of monitoring that difference will disappear and then the results in-depth will converge to the real values much better.

It has to be kept in mind that soil moisture measurements reflect the conditions of the particular station, while the model reflects the averaged soil and land cover characteristics for an area of $25 \mathrm{~km}^{2}$. Hence, the model values are more indicative for regional governance assessments. The performed comparisons convince that the CLM is a reliable tool for implementation of the soil moisture estimation and consequently for Soil Moisture Index monitoring for the whole country territory. 


\section{MAPPing the Soll Moisture IndeX (SMI) FOR 2013}

As an example for application of the above described methodology the soil moisture monthly average value at $30 \mathrm{~cm}$ soil depth and respectively the SMI during the year 2013 were computed. The SMI values distribution on the country territory is marked on GIS maps for every month [1]. One should have in mind when analysing the presented SMI pictures that the soil moisture at such small depth depends strongly on the precipitations, air temperatures and solar radiation in the month, as well as of course, on the soil profile properties and land cover. For that reason, as illustration below presented and briefly commented are the SMI and precipitation maps only of three climatically more characteristic for the 2013 months - January, May and June.

The SMI map of January (Fig. 1a) shows low moisture conditions in the country

(a)

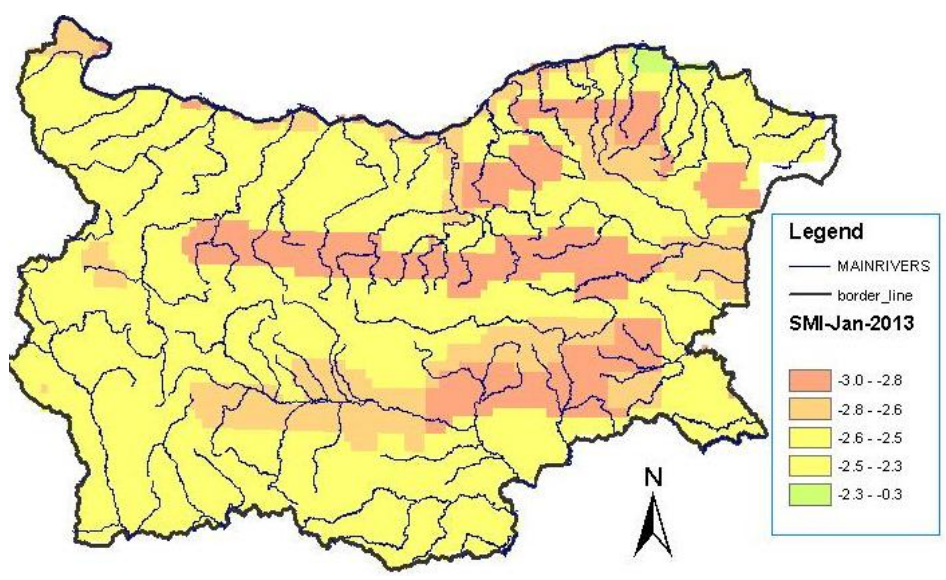

(b)

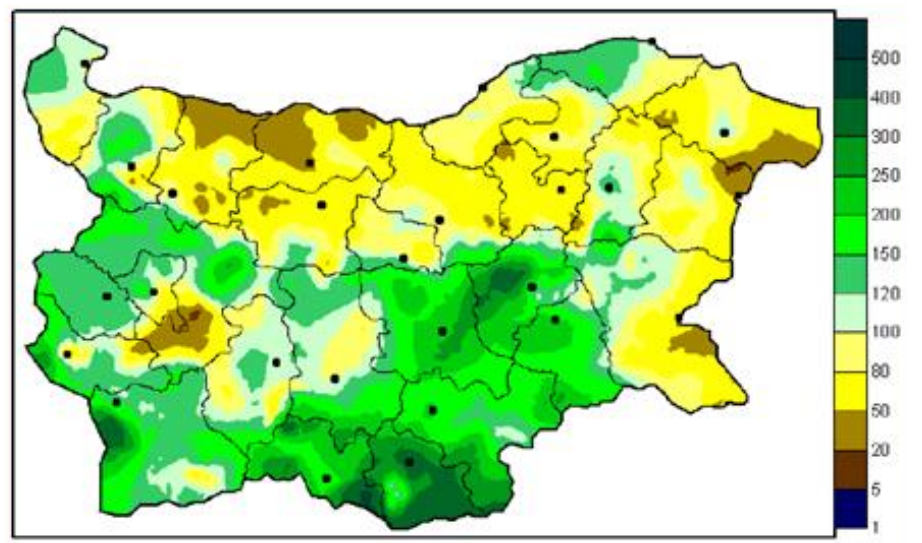

Fig. 1. SMI distribution (a) and precipitations distribution in \% of climatic norm (b) in January 2013. 
with a trend to the drought increase in East Bulgaria. The precipitations monthly sum is lower than the normal one and from East to West varies from 42 to $123 \%$ of the climatic norm (Bulgarian National Institute of Meteorology and Hydrology, bulletin 01.2013) [11]. Having in mind the winter air temperatures leading to low evapotranspiration, the computed moisture (Fig. 1a) corresponds to the conditions. There is reduced humidity in the Balkan mountain region, which is present in all months of the year, which probably is due to the great slopes and the precipitations quick runoff. The air temperatures were positive reaching $6^{\circ} \mathrm{C}$ above the climatic norm.

A strong deepening of the drought is observed in May. The precipitations monthly sums are much under the climatic norm for this month - between $30 \%$ and $120 \%$ of

(a)

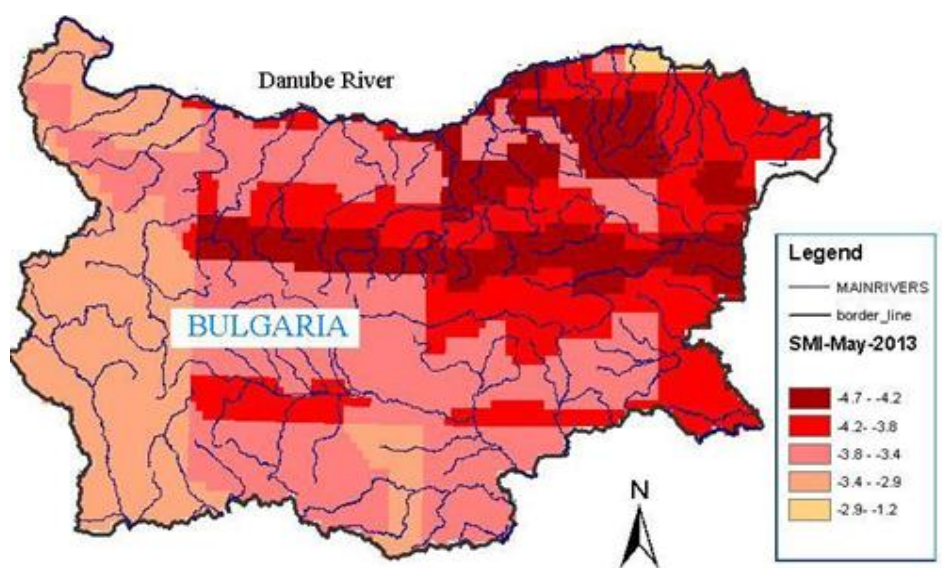

(b)

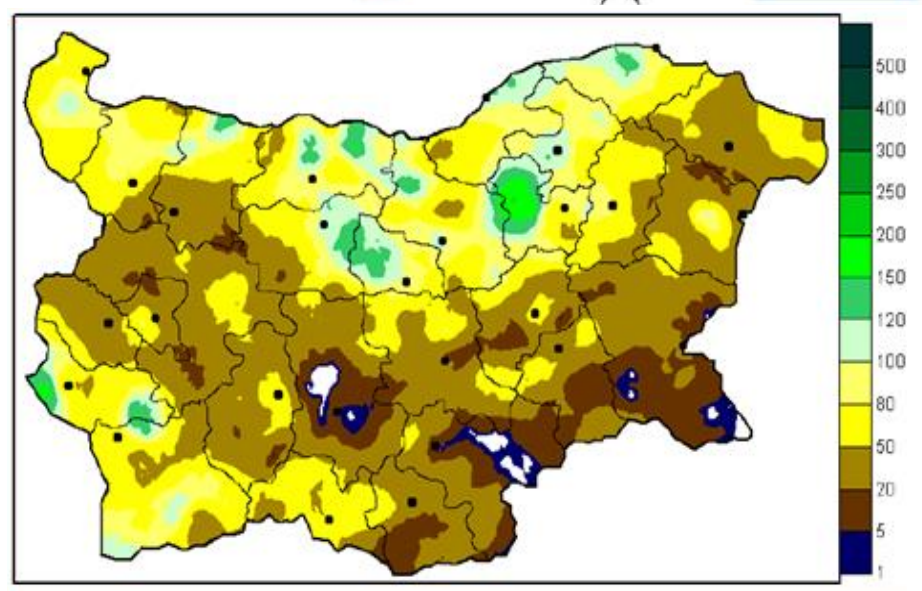

Fig. 2. SMI distribution (a) and precipitations distribution in \% of climatic norm (b) in May 2013. 
the norm for North and South-West Bulgaria and between 0 and $70 \%$ for East and South Bulgaria, respectively. The average monthly air temperatures are $4.5^{\circ} \mathrm{C}$ above the norm. Very logically, the drought degree nearly on the whole country land is so raised and in the North Bulgaria it reaches as high as -4.7 (SMI).

June precipitations on the greater part of the country are normal and above normal - varying between $90 \%$ and $360 \%$ of the norm (Fig. 3b). Only at the end, North-West and North-East territories the rains are scarce, as low as $20 \%$ of the norm. In the same time, the air temperatures are raised. The SMI picture (Fig. 3a) shows significant betterment of the soil moisture conditions, except on the mentioned above parts of the country with low precipitations compared to those in May and well corresponds to climatic effects of the month.

(a)

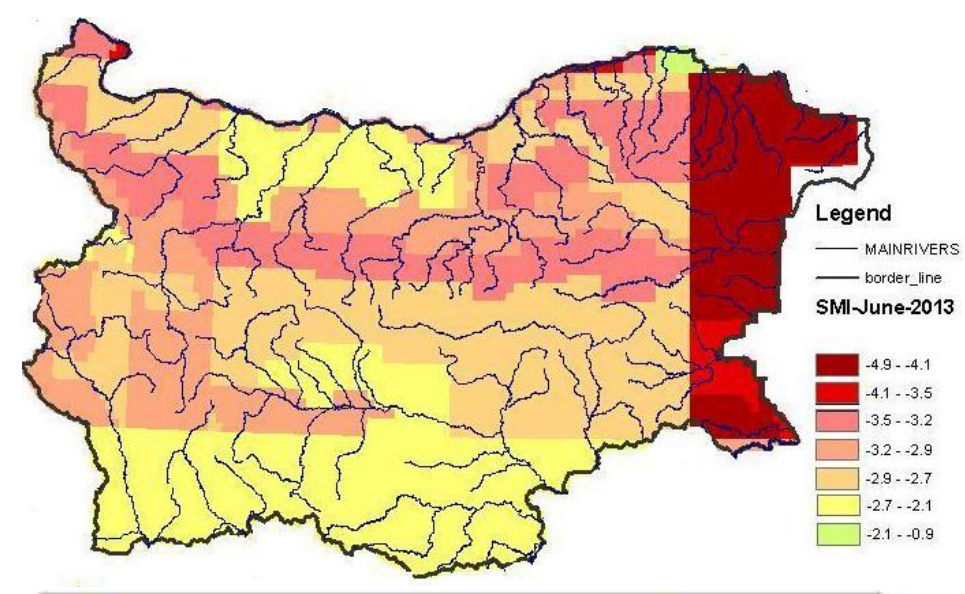

(b)

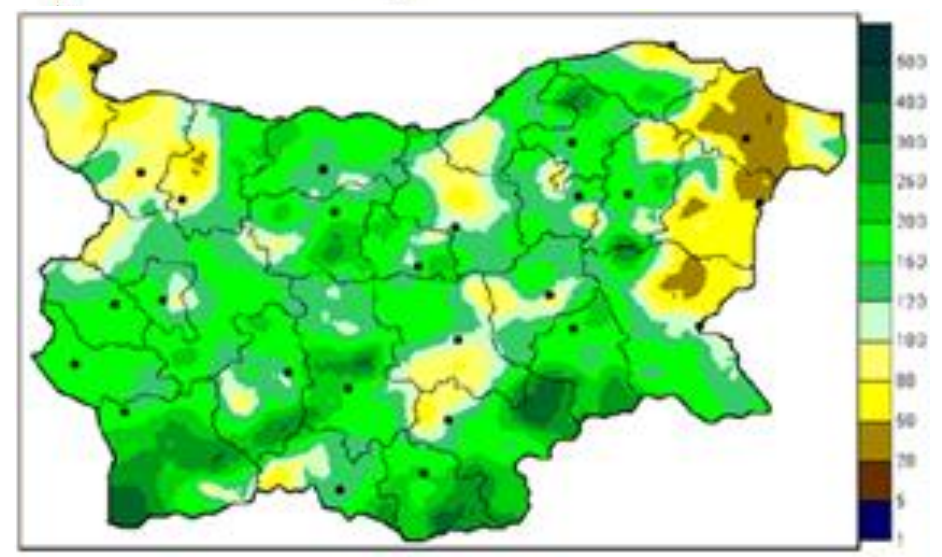

Fig. 3. SMI distribution (a) and precipitations distribution in \% of climatic norm (b) in June 2013. 


\section{CONCLUSIONS}

The soil moisture and the SMI on vast territories, respectively can be successfully estimated by spatially distributed mathematical models. The employed in the study CLM model, by many explained in the paper considerations, is rather suitable for this task. The obtained SMI maps well correspond to the observed climatic effects, influencing the soil moisture. Given the high dynamics of the latter at $30 \mathrm{~cm}$ soil depth, we believe that the average monthly value of the SMI is not sufficiently informative to assess the current state of the soil moisture. It would be better to perform this at ten days intervals. The SMI values are important information for the agricultural as well as the fire and flood safety management on a country scale. This information will be especially useful for irrigation planning and other agricultural measures, when it is assessed for future periods on the basis of climatic prognosis.

\section{REFERENCES}

[1] De JAGer, A., J. Vogt. Development and Demonstration of a Structured Hydrological Feature Coding System for Europe. Hydrol. Sci. J., 55 (2010), No. 5, 661-675.

[2] Horion, S., H. Carrão, A. Singleton, P. Barbosa, J. Vogt. JRC Experience on the Development of Drought Information Systems. Europe, Africa and Latin America, JRC Scientific and Technical Report, Publication office of the European Union, (2012), DOI 10.2788/15724.

[3] Kalnay et Al. The NCEP/NCAR 40-year Reanalysis Project. Bull. Amer. Meteor. Soc., 77 (1996), 437-470.

[4] KaZandiev, V., O. Nitcheva. Assessment of the Groundwater Recharge to Groundwater Body Bellene by the CLM Model. Water Affairs Journal, 1-2 (2013), 141-150.

[5] Niemeyer, S., A. De Jager, B. Kurnik, G. Laguardia, D. Magni, O. Nitcheva, S. Rossi, C. Weissteiner. Current State of Development of the European Drought Observatory. Geophysical Research Abstracts, 11 EGU2009-12802 (2009), http: / / adsabs . harvard.edu/abs/2009EGUGA . .1112802N

[6] Nitcheva, O., V. KaZAndjIev, Sv. Hristov. Soil Moisture for the Territory of Bulgaria, calculated by the CLM Model. Bulgarian Journal of Meteorology and Hydrology. 17 (2012), No. 5, 34-39.

[7] Nitcheva, O., V. Kazandjiev. Observed and Modelled Soil Moisture in Bulgaria, Satellite Soil Moisture Validation \& Application Workshop (no. 2854785), Italy, 1-3 July 2013, http: //esaconferencebureau.com/docs / default-source/13c13 textunderscoredocs $/ 7-$. pdf? sfvrsn $=\underline{0}$.

[8] Nitcheva, O., B. Milev, L. Hrischev. Management of Natural Hazards. Water Affairs Journal, 1-2 (2016), 9-13.

[9] Oleson, K. W. ET AL. Technical Description of the Community Land Model (CLM), NCAR Tech. Note NCAR/TN-461+STR, Natl. Cent. for Atmos. Res., Boulder, Colo, 2004, p. 173. 
Computation and Monitoring of the Soil Moisture Index on Bulgarian Territory 93

[10] Venkataramana, S., K. G. Hubbard, J. You, E. D. Hunt. Development of the Soil Moisture Index to quantify Agricultural Drought and its "User Friendliness" in Severity-area-duration Assessment. J. Hydrometeor, 9 (2008), 660-676.

[11] Bulgarian National Institute of Meteorology and Hydrology, Monthly Buletins, 2013. 